Research Article

\title{
Investigation of Heat Stepping Process for Epoxy-Amine Binders
}

\author{
Petro Stukhlyak, Andrii Mykytyshyn, and Ihor Chykhira $\mathbb{D}$ \\ Department of Computer-Integrated Technologies, Ternopil Ivan Puluj National Technical University, 56 Ruska Str., \\ Ternopil, Ukraine \\ Correspondence should be addressed to Ihor Chykhira; ig.vi.chi@gmail.com
}

Received 14 February 2020; Revised 22 May 2020; Accepted 17 July 2020; Published 5 August 2020

Academic Editor: Davide Palumbo

Copyright (c) 2020 Petro Stukhlyak et al. This is an open access article distributed under the Creative Commons Attribution License, which permits unrestricted use, distribution, and reproduction in any medium, provided the original work is properly cited.

\begin{abstract}
It is determined that in order to create a protective coating with high physical, mechanical, and thermophysical characteristics, it is necessary to carry out the appropriate heat stepping during its formation. The relevance of such processing mode use providing the increase of physical-mechanical and operational characteristics of epoxy material coatings due to the structure-forming processes in the material is substantiated.
\end{abstract}

\section{Introduction}

The reliability and durability of products based on epoxy oligomers depend on the thermal time hardening mode, the correct selection of which provides coatings with optimal service and technological properties.

It is proved that the heat treatment of composite materials significantly improves their physical and mechanical characteristics, including the matrix itself [1-4]. The possibility of further improvement of these characteristics is achieved by the automation of materials in the heat treatment process. As a rule, after product forming from the material based on cold hardening epoxy binders, it is kept for 24 hours at normal temperatures and then heat-treated at temperatures 393-403 K [5]. It is determined that the matrix crosslinking degree increases with the thermal treatment of the matrix $[3,4]$. The increase of the gel fraction yield during material formation is defined. At these temperatures, almost all physical units in the epoxy binder are destroyed [1]. In this case, the mobility of macromolecules increases, creating conditions for additional structuring in the matrix. The authors propose to carry out the epoxy material stepping in several stages $[6,7]$. It is proved that due to the creation of conditions under which the increase in the macromolecules mobility at temperatures higher than the glass transition temperature is observed, the structuring processes are refined. Such change in the conformational macromolecules set improves the physical and mechanical properties of the heat-treated material.

The investigation of the influence of formed material stepping at temperatures below $393 \mathrm{~K}$ on the matrix properties during automatic temperature control is of great interest from the scientific and practical point of view when choosing heat treatment modes.

The objective of this paper is to investigate the influence of the formed materials' stepping process for the improvement of the matrix properties by increasing the degree of crosslinking while improving the structuring processes in the binder.

\section{Materials and Methods of Investigation}

The epoxy diane oligomer of ED-20 grade (ISO 18280: 2010) polyethylene polyamine hardener is chosen as a binder for the investigation of heat stepping influence on the material properties. By binder (matrix), we mean a two-component mixture comprising epoxy resin and polyethylene polyamine. After hardening, as well as under the heat action, the processing forms samples for research. Such material is hardened at room temperature. The material forming is performed at $293 \mathrm{~K}$ for 24 hours. Ingredient ratio is ED-20100 and 10 weight parts of polyethylene polyamine (PEPA), 
which corresponds to the stereochemical component ratio. Then, the material is treated at temperature $T=393 \mathrm{~K}$ for $t=2$ hours. The material is heat-treated according to the stepping heating and cooling modes. Polyethylene polyamine is used for epoxy resin crosslinking. Polyethylene polyamine is a binder component and is aligned with it. When aligned, polyethylene polyamine reveals the oxide groups of epoxy macromolecules. During chemical interaction of the opened epoxy groups between themselves, the polymeric grid from macromolecules is formed. Isothermal treatment improves the grid formation due to changes in the confirmation set of macromolecules and Bow Group increases the degree of binder crosslinking (matrix).

Nicolet 380 IR spectrometer (Thermo Electron Corporation, USA) is used to investigate the structuring processes. Compressed powder in the form of the film containing $1 \mathrm{mg}$ of the investigated substance and $150 \mathrm{mg}$ of $\mathrm{KBr}$ is used in the infrared spectrometer.

The values of the limiting wetting angle are examined using the microscope of MBS-6 grade with "Olympus C-8080" camera. The physical sense of the investigated limiting wetting angle is to determine the geometric drops dimensions and their variations in time. It is proved by the investigations that after $\tau=20 \ldots 25 \mathrm{~min}$., the latter is almost unchanged. As the investigation duration extends, the change in the composites' wetting angle is within the error margin of the experiment.

The composite destructive stress during bending is determined according to ASTM D 790-03. The investigating sample is placed on two supports loaded up to fracture and load and strain values are recorded. The elasticity modulus is determined according to ASTM D 790-03, and it is the stress ratio to the corresponding relative strain increment. In order to define the internal stresses of polymer composite material, the console method is used. The differences in the free end deviation of the fixed sample with the coating in time are determined. The sample hardening degree is determined by the gel fraction content (Soxhlet apparatus).

At least 5 tests are carried out for statistical analysis of the investigation results. The arithmetic mean value of all parallel experiments is determined, and the Student criterion is used to eliminate the false values.

\section{Results and Discussion}

According to IR spectroscopy, the conversion degree of epoxy groups during hardening by ED-20 polyethylene polyamine at $293 \mathrm{~K}$ for 24 hours is $62 \%$ (Table 1). Further spectra analysis reveals that the absorption bands of free amino groups completely disappear. The formation of a homogeneous structure throughout the whole polymer composite volume is defined by optical microscopy. The elasticity modulus of pure binder tensile strength is $E=47.60 \mathrm{MPa}$. After heat treatment at $393 \mathrm{~K}$ for 2 hours, the residual stresses in coatings are $\sigma_{3}=3.0-3.33 \mathrm{MPa}$. Further, the stepping is performed. The results of such treatment effect on the binder properties are presented in Table 1. Within the next 10 days, the hardening degree determining by the content of the gel fraction increases by $10 \%$ and is
$72 \%$. As a result of structuring processes, the elasticity modulus increases by $9 \%$, which is explained by the increase of the epoxy binder spatial grid density. Further increase in the crosslinking extent at the given temperature does not occur for 25-30 days. The obtained results are in good agreement with the known data that while hardening the epoxy compositions at low temperatures up to $1 / 3$ of epoxy groups does not react due to steric problems $[8,9]$ and the occurrence of physical units at a temperature below the glass transition temperature $\left(T_{c}\right)$ is $T_{c}=393-395^{\circ} \mathrm{K}$.

In order to ensure greater complete compositions hardening after 24 hours of exposure at $293 \mathrm{~K}$, the sample heat treatment at $393 \mathrm{~K}$ using an automated device for heat treatment process control is carried out. The block diagram of the device is shown in Figure 1.

The device operates in the following way. The temperature in the furnace is measured by a thermocouple and is fed to the controller via the analog-digital converter, which, depending on the temperature value and set mode, outputs the control signal to the thermostat to increase or decrease the furnace heat. You are able to control the process by a personal computer that is connected to the controller by means of an interface converter. New heat treatment modes are also set new.

It is determined that with the increase of material formation temperature, the number of unreacted functional groups decreases, the composition structure formation degree increases, and the chemical grid with a greater degree of crosslinking volume is formed. It should be noted that in the grid formation at temperatures below $T_{c}$, the structural processes in the binder are observed. However, as the result of reducing the chain section length between the crosslinking units, including those reduced by means of physical interaction, the binder macromolecule mobility and the structuring processes are reduced. With the increase of heat treatment temperature greater than $393 \mathrm{~K}$, the speed of the crosslinking process increases significantly. Cohesive strength decreases due to the increase of internal stresses in the epoxy composite, as well as the occurrence of heterogeneous structure in the material. The increase of residual stresses at high adhesion of epoxy compositions to the metal surface causes protective coatings cracking, especially at the edges and, as a consequence, results in their separation.

For further improvement and support of high stability of operational and technological characteristics of epoxy composites in real conditions of long-term operation while choosing the optimum treatment mode, the composite heat stepping is also carried out taking into account the investigations of their hardening kinetics.

Based on the previous results of the investigations of the epoxy composites hardening kinetics, new modes of materials stepping heating are proposed (Figure 2 and Table 2) taking into account isothermal effects, their intensity, and time of manifestation in the hardening process.

The start of heating time $\left(t_{1}\right.$ and $\left.t_{2}\right)$ and treatment duration $\left(\tau_{1}\right.$ and $\left.\tau_{2}\right)$ are selected on the basis of the investigation results of epoxy composites mechanical loss tangent in the process of material forming into products [10]. The extremes on the dependence graph $\operatorname{tg} \delta$ correspond 
TABLE 1: The effect of hardening conditions on the binder properties based on ED-20.

\begin{tabular}{lcccc}
\hline \multirow{2}{*}{ Indicator } & \multicolumn{3}{c}{ Hardening mode } \\
& 24 hours & 240 hours & 720 hours & 24 hours at 293 K and 2 hours at 393 K \\
\hline Hardening degree, $X(\%)$ & 62 & 72 & 73 & 88 \\
Wetting angle, $\alpha$ (deg.) & 31 & 36 & 44 & 53 \\
Elasticity modulus under bending, E $(\mathrm{MPa})$ & 1540 & 1680 & 1710 & 1810 \\
Internal, $\sigma_{\mathrm{BH}}(\mathrm{MPa})$ & 0.5 & 0.9 & 1.2 & 1.6 \\
Destructive bending stress, $\sigma_{\mathrm{p}}(\mathrm{MPa})$ & 28.2 & 39.1 & 42.3 & 46.1 \\
\hline
\end{tabular}

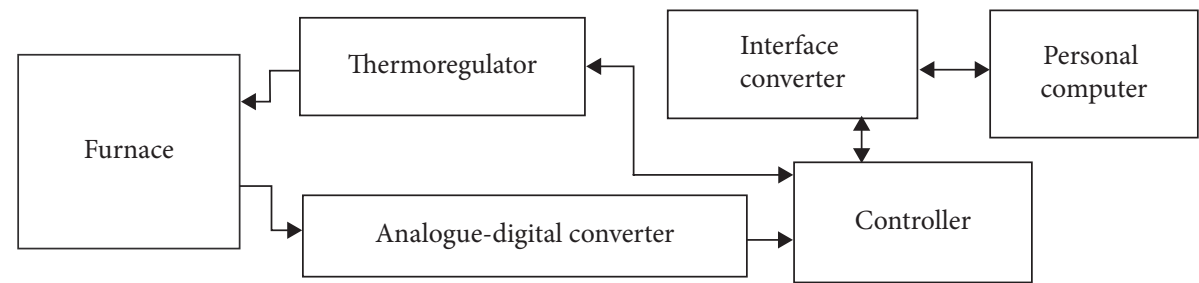

FiguRE 1: Block diagram of automated control of the heat treatment process.

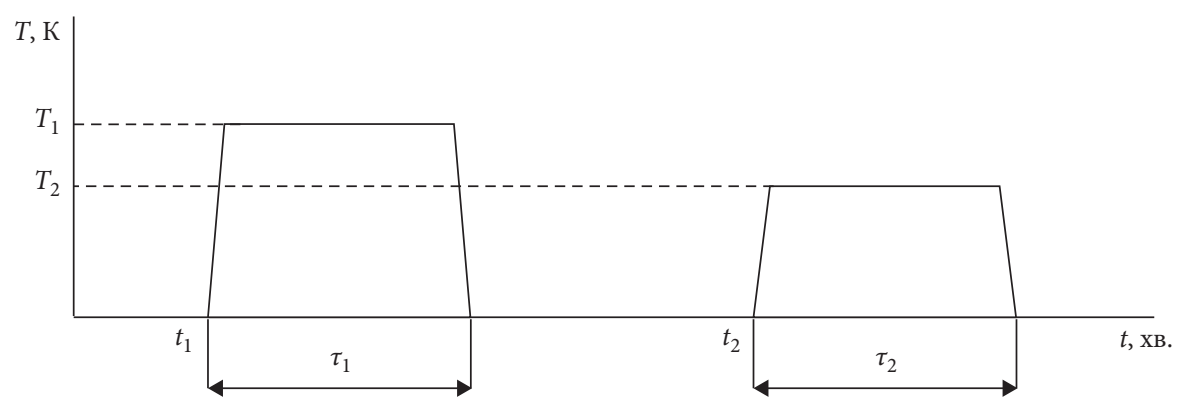

FIGURE 2: Scheme of heat stepping mode of PCM taking into account the isothermal effects occurring during hardening.

TABLE 2: The parameters of compositions stepping based on epoxide resin hardened by PEPA.

\begin{tabular}{|c|c|c|c|c|c|c|}
\hline \multirow[t]{2}{*}{ \# Comp. } & \multicolumn{2}{|c|}{$\begin{array}{l}\text { Starting times for } \\
\text { heating (cooling), min }\end{array}$} & \multicolumn{2}{|c|}{$\begin{array}{l}\text { Duration of heating } \\
\text { (cooling), min }\end{array}$} & \multicolumn{2}{|c|}{$\begin{array}{l}\text { Isothermal treatment } \\
\text { temperature } T_{i}, \mathrm{~K}\end{array}$} \\
\hline & $t_{1}$ & $t_{2}$ & $\tau_{1}$ & $\tau_{2}$ & $\mathrm{~T}_{1}$ & $\mathrm{~T}_{2}$ \\
\hline 1 & \multicolumn{6}{|c|}{ Room temperature } \\
\hline 2 & 20 & 100 & 35 & 30 & 313 & 303 \\
\hline 3 & 20 & 100 & 35 & 30 & 333 & 303 \\
\hline 4 & 0 & 100 & 35 & 30 & 333 & 313 \\
\hline 5 & - & 100 & - & 30 & - & 323 \\
\hline 6 & 20 & 100 & 35 & 30 & 353 & 313 \\
\hline 7 & 20 & - & 180 & - & 353 & - \\
\hline
\end{tabular}

to the material heat stepping modes. The correlation between these extremes and the heat treatment duration is also observed. The processing temperature $(t)$ is chosen in the area $T=293 \div 353 \mathrm{~K}$.

Due to the thermomechanical analysis and console method for elasticity modulus determination, it is possible to define the glass transition temperature $\left(\mathrm{T}_{\mathrm{C}}\right)$ of epoxy composite materials investigated in the form of metal-based coatings by the nature of the stress changes curve [10]. Figure 3 shows the dependence of the internal stresses change on the temperature in the coatings based on epoxy resin and PEPA formed on the steel plate and hardened according to the specified heat treatment modes (Figure 2 and Table 2).

It is evident from Figure 3 that the curves of temperature dependence of the internal stresses in coatings are nonmonotonic. The minimum stress corresponds to the epoxy composites' glass transition temperature. The maximum indicates the flow of additional structuring processes. Therefore, the analysis of these results proves that the highest glass transition temperature corresponds to the coating on the basis of thermally treated composition no. 3 . In this case, $T_{C}$ for coating treated under specified mode increases by $22 \mathrm{~K}$ compared to the coating maintained at room temperature. 


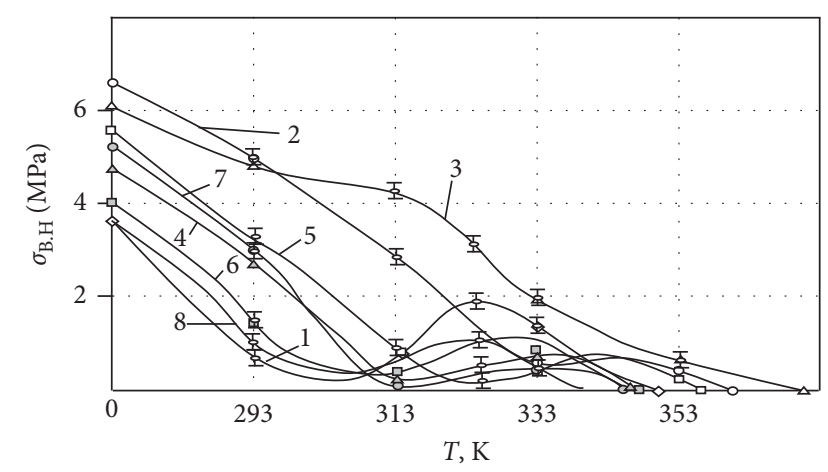

FIGURE 3: Dependence of internal stresses change on temperature for compositions on the basis of epoxy resin hardened by modes: 1 : $\mathrm{T}=293 \mathrm{~K}, 72$ hours; 2: $\mathrm{T}=393 \mathrm{~K}, 2$ hours; $3: \mathrm{T}=293 \mathrm{~K}, 72$ hours, $\mathrm{T}_{1}=313 \mathrm{~K}, \quad \mathrm{~T}_{2}=303 \mathrm{~K} ; 4: \mathrm{T}=393 \mathrm{~K}, 2$ hours, $\mathrm{T}_{1}=313 \mathrm{~K}$, $\mathrm{T}_{2}=303 \mathrm{~K} ; 5: \mathrm{T}=293 \mathrm{~K}, 72$ hours, $\mathrm{T}_{1}=333 \mathrm{~K}, \mathrm{~T}_{2}=313 \mathrm{~K} ; 6$ : $\mathrm{T}=393 \mathrm{~K}, 2$ hours, $\mathrm{T}_{1}=333 \mathrm{~K}, \mathrm{~T}_{2}=313 \mathrm{~K} ; 7: \mathrm{T}=293 \mathrm{~K}, 72$ hours, $\mathrm{T}_{1}=353 \mathrm{~K}, \mathrm{~T}_{2}=323 \mathrm{~K} ; 8: \mathrm{T}=393 \mathrm{~K}, 2$ hours, $\mathrm{T}_{1}=353 \mathrm{~K}$, $\mathrm{T}_{2}=323 \mathrm{~K}$.

The flow of structuring processes in the matrix is also confirmed by the change in their elasticity modulus under bending when the temperature changes (Figure 4). For coating based on composition no. 3 (curve 3), the value of the elasticity modulus first sharply decreases, and then, it almost does not change with temperature. The horizontal area of this curve characterizes the conditionally equilibrium elastic modulus of the structured composite.

For coating material hardened at room temperature, the sharp decrease of the elasticity modulus under bending while changing the temperature $(\mathrm{T}=393 \mathrm{~K})$ is observed. But when the minimum value is reached, it starts to increase with further temperature rise. The module value asymptotically approaches the value of equilibrium elasticity modulus of the coating material formed on composition no. 2 basis.

It is determined that the heat treatment of epoxy coatings increases the material crosslinking degree. The value of the limiting wetting edge angle is an indicator of the crosslinking degree as the number of functional groups in the material decreases. The qualitative indicators of these processes are evaluated by the limiting wetting angle. The correlation of adhesion characteristics and the limiting wetting angle is also proved. These results are in good agreement with the results of the paper [11].

The given data (Table 1) show that the minimum wetting angle corresponds to the composite crosslinked at $293 \mathrm{~K}$ for 24 hours and is $31^{\circ}$ at a hardening rate of $62 \%$. Increasing the crosslinking temperature and, relatively, the composition hardening degree increases the wetting angle. The increase of the wetting angle at treatment temperature rise can be explained by the decrease in the composite surface energy, associated with the decrease in the active functional group concentration being in good agreement with the materials of paper [11].

The composition is hardened at temperature $293 \mathrm{~K}$ for 72 hours and then heat-treated at temperature $393 \mathrm{~K}$ for 2 hours. Further, the stepping is performed according to the scheme shown in Figure 2, where $T_{1}$ is changed from 313 to

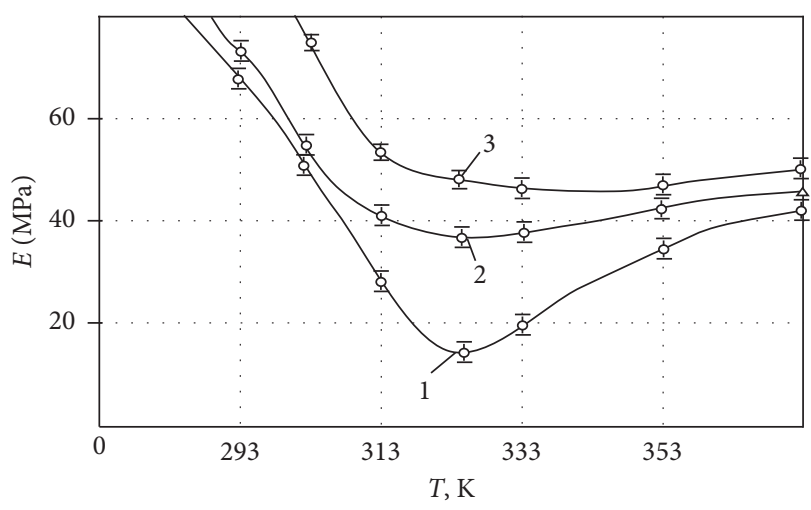

FIgURE 4: The dependence of elasticity modulus change under bending on temperature for compositions based on epoxy resin, hardened according to the modes given in Table 1 (curve numbers correspond to composition numbers given in Table 2).

$353 \mathrm{~K}$ at $20 \mathrm{~K}$ intervals and $\mathrm{T}_{2}$ from 303 to $323 \mathrm{~K}$ at $10 \mathrm{~K}$ intervals.

It is determined that the composition formation at $293 \mathrm{~K}$ and subsequent heat treatment improves the impact toughness $\mathrm{a}=8.7 \mathrm{~kJ} / \mathrm{m}^{2}$ to $9.25 \mathrm{~kJ} / \mathrm{m}^{2}$, and the heat resistance increases by $17-18 \mathrm{~K}$. It is proved that the increase in the temperature of additional stepping with $\mathrm{T}_{1}=313 \mathrm{~K}$ and $\mathrm{T}_{2}=303 \mathrm{~K}$ to $\mathrm{T}_{1}=353 \mathrm{~K}$ and $\mathrm{T}_{2}=323$ increases the impact toughness to $\mathrm{a}=9.45 \mathrm{~kJ} / \mathrm{mm}^{2}$ and heat resistance to $375 \mathrm{~K}$.

\section{Conclusions}

The correlation dependence of the heat stepping modes with physical-mechanical and structural characteristics of the developed epoxy binders is proved. While creating composite materials with high operational properties, it is necessary to carry out the following thermal treatment, including stepping: expose time 24 hours at $293 \mathrm{~K}$ followed by heat treatment at temperature $393 \mathrm{~K}$ for 2 hours, then the material treatment at temperature $333 \mathrm{~K}$ for 35 minutes, then holding at temperature $293 \mathrm{~K}$ for 45 minutes, and further holding at $313 \mathrm{~K}$ for $30 \mathrm{~min}$.

In future, we plan to investigate the effect of various organic modifiers and stepping on the modified matrix properties. The following material will be used as a binder for composites containing nanoadditives and discrete and longdimensional fibers.

\section{Data Availability}

The data used to support the findings of this study are available from the corresponding author upon request.

\section{Conflicts of Interest}

The authors declare that they have no conflicts of interest.

\section{References}

[1] L. H. Sperling, "Interpenetrating Polymer Networks," Encyclopedia of Polymer Science and Technology, Wiley, Hoboken, NJ, USA, 2004. 
[2] F.-L. Jin, X. Li, and S.-J. Park, "Synthesis and application of epoxy resins: a review," Journal of Industrial and Engineering Chemistry, vol. 29, pp. 1-11, 2015.

[3] A. J. Kinloch, S. H. Lee, and A. C. Taylor, "Improving the fracture toughness and the cyclic-fatigue resistance of epoxypolymer blends," Polymer, vol. 55, no. 24, pp. 6325-6334, 2014.

[4] O. Robert, Ebewele Polymer Science and Technology, p. 544, CRC Press, Boca Raton, FL, USA, 2000.

[5] H. He, K. Li, J. Wang, G. Sun et al., "Study on thermal and mechanical properties of nano-calcium carbonate/epoxy composites," Materials \& Design, vol. 32, no. 8-9, pp. 4521-4527, 2011.

[6] P. P. Savchuk, A. G. Kostornov, and V. P. Kashytsky, Influence of Technological Parameters on Properties of Epoxy Composition Materials, pp. 56-64, Bulletin of Vasyl Stefanyk Precarpathian National University, Ivano-Frankivsk, Ukraine, 2008.

[7] N. G. Leonova, V. M. Mikhal'chuk, Y. P. Mamunya, V. V. Davydenko, and M. V. Iurzhenko, "Thermophysical properties of epoxy-polysiloxane composites of cationic polymerization," Polymer Science Series D, vol. 6, no. 3, pp. $210-217,2013$.

[8] A. V. Akimov, A. V. Buketov, O.O. Sapronov, M. V. Brailo, S. V. Yakushchenko, and S. A. Smetankin, "Development of polymer composites with improved thermophysical properties for shipbuilding and ship repair," Composites: Mechanics, Computations, Applications: An International Journal, vol. 10, no. 2, pp. 117-134.

[9] A. Buketov, M. Brailo, S. Yakushchenko, and A. Sapronova, "Development of epoxy-polyester composite with improved thermophysical properties for restoration of details of sea and river transport," Advances in Materials Science and Engineering, vol. 2018, Article ID 6378782, 6 pages, 2018.

[10] A. Mykytyshyn, P. Stuchlyak, M. Mytnyk, and O. Zablotskyi, "Investigation of the epoxycomposites hardening processes according to their properties," Scientific Journal of TSTU (Tern.), vol. 12, no. 3, pp. 27-33, 2007.

[11] O. O. Sapronov, A. V. Buketov, D. O. Zinchenko, and V. M. Yatsyuk, "Features of structural processes in epoxy composites filled with silver carbonate on increase in temperature," Composites: Mechanics, Computations, Applications: An International Journal, vol. 8, no. 1, pp. 47-65, 2017. 